TITLE:

\title{
Molecular Phylogeny of the Diversified Frogs of Genus Fejervarya (Anura: Dicroglossidae)
}

\section{$\operatorname{AUTHOR}(S)$ :}

Kotaki, Manabu; Kurabayashi, Atsushi; Matsui, Masafumi; Kuramoto, Mitsuru; Djong, Tjong Hon; Sumida, Masayuki

\section{CITATION:}

Kotaki, Manabu ...[et al]. Molecular Phylogeny of the Diversified Frogs of Genus Fejervarya (Anura: Dicroglossidae). Zoological Science 2010, 27(5): 386-395

\author{
ISSUE DATE: \\ 2010-05 \\ URL: \\ http://hdl.handle.net/2433/216894 \\ RIGHT: \\ (C) 2010 Zoological Society of Japan
}




\title{
Molecular Phylogeny of the Diversified Frogs of Genus Fejervarya (Anura: Dicroglossidae)
}

\author{
Manabu Kotaki ${ }^{1}$, Atsushi Kurabayashi ${ }^{1}$, Masafumi Matsui ${ }^{2}$, \\ Mitsuru Kuramoto ${ }^{3}$, Tjong Hon Djong ${ }^{1,4}$ \\ and Masayuki Sumida ${ }^{1 *}$ \\ ${ }^{1}$ Institute for Amphibian Biology, Graduate School of Science, Hiroshima University, \\ Higashihiroshima 739-8526, Japan \\ ${ }^{2}$ Graduate School of Human and Environmental Studies, Kyoto University, \\ Kyoto 606-8501, Japan \\ ${ }^{3}$ Hikarigaoka, Munakata, Fukuoka 811-3403, Japan \\ ${ }^{4}$ Department of Biology, Faculty of Science, Andalas University, \\ Padang 25136, West Sumatra, Indonesia
}

\begin{abstract}
Consensus on the taxonomic system and phylogenetic relationships for the anuran genus Fejervarya has yet to be established. Morphological characters in this genus are generally unsuitable for species identification. To carry out molecular species identification and solve phylogenetic problems, we collected 67 Fejervarya specimens from 12 Asian countries and sequenced part of the mitochondrial (mt) Cytb gene. We also sequenced the mt 125 and 16S rRNA genes and seven nuclear genes (BDNF, CXCR4, NCX1, RAG-1, RAG-2, Rhod, and Tyr) for 25 Fejervarya taxa. These molecular markers appear to be adequate for the identification of species. We subjected the molecular data molecular to phylogenetic analyses. In the resulting trees, topotypic $F$ limnocharis and " $F$. multistriata" (from China) formed a clade. On the other hand, neither "F limnocharis" from the Japan mainland nor "F. limnocharis" from eastern Taiwan formed a clade with the real $F$. limnocharis, and the genetic divergences were larger than the species threshold for frog taxa proposed in previous studies $(>3 \%$ for $16 S)$. These results may suggest that " $F$ multistriata" is a junior synonym of $F$. limnocharis, or that only some of the populations now recognized as " $F$ multistriata" correspond to $F$ limnocharis. Our results also suggest that several cryptic species may be included among the widely distributed Fejervarya species. Finally, our datasets support paraphyly for the genus Fejervarya, although alternative phylogenetic topologies, including Fejervarya monophyly, were not rejected by $\mathrm{KH}$ and $\mathrm{SH}$ tests.
\end{abstract}

Key words: sequence divergence, molecular phylogeny, mitochondrial genes, nuclear genes, Fejervarya

\section{INTRODUCTION}

The anuran genus Fejervarya is widely distributed in Asia (Frost, 1985); 34 nominal Fejervarya species are currently known (Frost, 2009). Despite the many morphological and molecular studies conducted (e.g., Stuart et al., 2006; Djong et al., 2007a; Matsui et al., 2007), a consensus on the taxonomic system and phylogenetic relationships related to this genus is far from established. The open controversies have two principal causes. First, the monophyletic nature of this genus is problematic. Frost et al. (2006) showed the nested grouping of Fejervarya and several other genera (Hoplobatrachus, Euphlyctis, Nannophrys, and Sphaerotheca), and Kotaki et al. (2008) suggested paraphyly

\footnotetext{
* Corresponding author. Phone: +81-82-424-7482; Fax : +81-82-424-0739;

E-mail: msumida@ hirosima-u.ac.jp
}

Supplemental material for this article is available online at http://dx.doi.org/10.2108/zsj.27.386.s1.

doi: $10.2108 / z s j .27 .386$ for this genus. Second, accurate identification of Fejervarya species is difficult for the following reasons. 1) About half of the 34 Fejervarya species were described in the 19th century and early 20th century (Frost, 2009), and access to type specimens is difficult. 2) In some cases, only poor morphological diagnoses are available. For some Fejervarya groups (e.g., the Fejervarya limnocharis complex), there are very few diagnostic morphological features. 3) Several cryptic species have been found from Fejervarya populations formerly recognized as single nominal species (Dubois, 1975; Toda et al., 1998; Veith et al., 2001; Sumida et al., 2007; Islam et al., 2008a, 2008b), and there is a chance that many undescribed cryptic species will be found in certain Asian areas, where detailed surveys of the herpetological fauna have yet to be performed (Kuramoto et al., 2007). Several other Fejervarya species besides F. limnocharis also seem to be confusingly named, and erroneous identifications have been occasionally found (see the Discussion). Some of the errors were discovered from ecological and morphological studies (e.g., Dubois, 1975; Matsui et al., 2007). In the 
majority of cases, however, cryptic species and erroneous identifications were initially recognized through molecular markers (Toda et al., 1998; Veith et al., 2001; Kurabayashi et al., 2005; Djong et al., 2007a; Kuramoto et al., 2007; Sumida et al., 2007; Islam et al., 2008a). Thus, phylogenetic analyses with more abundant molecular data, the accumu- lation of sequence data from nominal species, and species surveys with specimens from many localities would be good approaches to clear up these problems.

In this study, we collected 67 Fejervarya specimens from 12 Asian countries and surveyed genetic divergences among and within populations by determining partial mito-

Table 1. Accession numbers for nucleotide sequences of three mitochondrial and seven nuclear genes. NA, not available.

\begin{tabular}{|c|c|c|c|c|c|c|c|c|c|c|c|c|c|c|}
\hline \multirow{2}{*}{ Species } & \multicolumn{2}{|c|}{ Collecting station } & \multirow{2}{*}{$\begin{array}{l}\text { No. of } \\
\text { frogs }\end{array}$} & \multicolumn{11}{|c|}{ Accession Nos. } \\
\hline & Country & Locality & & Cyt b & 12S rRNA & 16S rRNA & BDNF & CXCR4 & NCX1 & 3' RAG1 & 5' RAG1 & RAG2 & Rhodopsin & Tyrosinase \\
\hline F. cancrivora & Malaysia & Selangor & $1 A$ & AB488817 & AB488859 & AB488882 & AB500232 & AB500240 & AB500246 & AB500218 & AB500226 & NA & AB500255 & AB500263 \\
\hline F. caperata & India & Mudigere & $2 A$ & AB488843 & AB488871 & AB488894 & AB489055 & AB488912 & AB488929 & AB488946 & AB488970 & AB488990 & AB489031 & AB489010 \\
\hline F. granosa & India & Mudigere & $2 A$ & AB488844 & AB488872 & AB488895 & AB489056 & AB488913 & AB488930 & AB488947 & AB488971 & AB488991 & AB489032 & AB489011 \\
\hline F. greenii & Sri Lanka & Hakgala & $1 A$ & AB4888838 & AB488868 & AB488891 & AB489053 & AB488910 & AB488927 & AB488944 & AB488968 & AB488988 & AB489029 & AB489008 \\
\hline \multirow[t]{2}{*}{ F. iskandari } & Indonesia & Java & 1 & AB488813 & $\mathrm{AB} 277287^{\mathrm{a}}$ & $\mathrm{AB} 277303^{\mathrm{a}}$ & AB489045 & $\mathrm{AB} 277316^{\mathrm{a}}$ & AB277328 ${ }^{a}$ & AB488954 & AB277342 ${ }^{\mathrm{a}}$ & AB488981 & AB489021 & $A B 277355^{a}$ \\
\hline & & & 1 & AB488814 & AB2 $277287^{a}$ & AB277303 ${ }^{a}$ & NA & NA & NA & NA & NA & NA & NA & NA \\
\hline \multirow[t]{2}{*}{ F. kirtisinghei } & Sri Lanka & Hakgala & $1 A$ & AB488836 & AB488867 & AB488890 & AB489052 & AB488909 & AB488926 & AB488943 & AB488967 & AB488987 & AB489028 & AB489007 \\
\hline & & & $1 A$ & AB488837 & NA & NA & NA & NA & NA & NA & NA & NA & NA & NA \\
\hline F. kudremukhensis & India & Kudremukh & $2 t$ & AB488849 & AB488875 & AB488898 & AB489059 & AB488916 & AB488933 & AB488950 & AB488974 & AB488994 & AB489035 & AB489014 \\
\hline \multirow[t]{2}{*}{ F. limnocharis } & Indonesia & Java & 1 & AB488811 & AB277285 & $\mathrm{AB} 277292^{\mathrm{a}}$ & AB489044 & $\mathrm{AB} 277315^{\mathrm{a}}$ & AB277327 ${ }^{\mathrm{a}}$ & AB488953 & AB2 $277341^{a}$ & AB488980 & AB489020 & AB277354 $4^{a}$ \\
\hline & & & $1 A$ & AB488812 & AB277286 ${ }^{a}$ & $\mathrm{AB} 277302^{\mathrm{a}}$ & NA & NA & NA & NA & NA & NA & NA & NA \\
\hline F. limnocharis & Japan & Hiroshim & $1 A$ & AB488832 & AB488864 & AB488887 & AB489050 & AB488907 & AB488924 & AB488941 & AB488965 & AB488986 & AB489026 & BB489005 \\
\hline \multirow{3}{*}{ F. limnocharis } & Malaysia & Kuala Lumpur & $1 f$ & AB488815 & AB277275 & AB277301 ${ }^{\mathrm{a}}$ & NA & NA & NA & NA & NA & NA & NA & NA \\
\hline & & & 1 & AB488828 & $\mathrm{AB} 277275^{\mathrm{a}}$ & $\mathrm{AB} 277301^{\mathrm{a}}$ & NA & NA & NA & NA & NA & NA & NA & NA \\
\hline & & Sabah & 1 & AB488815 & AB277275 & AB277292 ${ }^{\mathrm{a}}$ & NA & NA & NA & NA & NA & NA & NA & NA \\
\hline \multirow[t]{2}{*}{ F. limnocharis } & Taiwan & Green Island & 2 & AB488829 & AB488862 & AB488885 & NA & NA & NA & NA & NA & NA & NA & NA \\
\hline & & Orchard Island & 2 & AB488829 & AB488862 & AB488885 & AB500233 & AB500241 & AB500247 & AB500219 & AB500227 & NA & AB500256 & AB500264 \\
\hline \multirow[t]{3}{*}{ F. limnocharis } & Thailand & Ranong & 1 & AB488816 & AB277278 ${ }^{a}$ & AB277292 ${ }^{a}$ & NA & $\mathrm{AB} 277307^{\mathrm{a}}$ & $\mathrm{AB} 277321^{\mathrm{a}}$ & NA & AB277333 ${ }^{a}$ & NA & NA & $\mathrm{AB} 277351^{\mathrm{a}}$ \\
\hline & & Tha Ton & $1 A$ & AB488818 & $\mathrm{AB} 277275^{\mathrm{a}}$ & AB277292 ${ }^{\mathrm{a}}$ & NA & $\mathrm{AB} 277307^{\mathrm{a}}$ & AB277322 ${ }^{a}$ & NA & AB277334 ${ }^{a}$ & NA & NA & AB277348 ${ }^{a}$ \\
\hline & & $\begin{array}{l}\text { Nakhon } \mathrm{Si} \\
\text { Thammarat }\end{array}$ & 1 & AB488819 & AB277275 & AB277292 & NA & $\mathrm{AB} 277307^{\mathrm{a}}$ & $A B 277321^{a}$ & NA & AB277336 & NA & A & $B 277347^{a}$ \\
\hline \multirow[t]{2}{*}{ F. cf. limnocharis } & Cambodia & & $1 A$ & AB488818 & NA & NA & NA & NA & NA & NA & NA & NA & NA & NA \\
\hline & & & $1 A$ & AB488833 & NA & NA & NA & NA & NA & NA & NA & NA & NA & NA \\
\hline F. cf. limnocharis & Laos & Phongsaly & 1 & AB488818 & NA & NA & NA & NA & NA & NA & NA & NA & NA & NA \\
\hline & & & 2 & AB488827 & NA & NA & NA & NA & NA & NA & NA & NA & NA & NA \\
\hline F. cf. limnocharis & Thailand & Chanta Buri & 3 & AB488818 & NA & NA & NA & NA & NA & NA & NA & NA & NA & NA \\
\hline & & Phang Nga & 1 & AB488823 & NA & NA & NA & NA & NA & NA & NA & NA & NA & NA \\
\hline & & & $1 A$ & AB488824 & NA & NA & NA & NA & NA & NA & NA & NA & NA & NA \\
\hline & & & 1 & AB488825 & NA & NA & NA & NA & NA & NA & NA & NA & NA & NA \\
\hline F. cf. limnocharis & Vietnam & Sapa & $3 t$ & AB488826 & NA & NA & NA & NA & NA & NA & NA & NA & NA & NA \\
\hline F. mudduraja & India & Madikeri & 1 & AB488845 & AB488873 & AB488896 & AB489057 & AB488914 & AB488931 & AB488948 & AB488972 & AB488992 & AB489033 & B489012 \\
\hline & & Ooty & 1 & AB488846 & NA & NA & NA & NA & NA & NA & NA & NA & NA & NA \\
\hline F. multistriata & China & Hainan & 1 & AB488828 & NA & NA & NA & NA & NA & NA & NA & NA & NA & NA \\
\hline & & Husa & 1 & AB488828 & AB488861 & AB488884 & AB500234 & AB500242 & AB500248 & AB500220 & AB500228 & AB500252 & AB500257 & B500265 \\
\hline F. multistriata & Taiwan & Taipei & $1 A$ & AB488828 & AB488861 & AB488884 & AB500235 & AB500243 & AB500249 & AB500221 & AB500229 & AB500253 & AB500258 & AB500266 \\
\hline F. orissaensis & India & Orissa & $2 A$ & AB488842 & AB277288 & AB277304 & AB500236 & $\mathrm{AB} 277317^{\mathrm{a}}$ & $A B 277329^{a}$ & AB500222 & $A B 277343^{a}$ & NA & AB500259 & AB277356 ${ }^{a}$ \\
\hline F. pierrei & Nepal & Chitwan & $2 A$ & AB488834 & AB488865 & AB488888 & AB489051 & AB488908 & AB488925 & AB488942 & AB488966 & AB490160 & AB489027 & AB489006 \\
\hline F. rufescens & India & Mangalore & 1 & AB488847 & AB488874 & AB488887 & AB489058 & AB488915 & AB488932 & AB488949 & AB488973 & AB488993 & AB489034 & AB489013 \\
\hline & & & $1 A$ & AB488848 & NA & NA & NA & NA & NA & NA & NA & NA & NA & NA \\
\hline F. sakishimaensis & Japan & Iriomote Island & $1 A$ & AB488831 & AB488863 & AB488886 & AB489049 & AB488906 & AB488923 & AB488940 & AB488964 & AB488985 & AB489025 & AB489004 \\
\hline & & Ishigaki Island & $1 A$ & AB488830 & NA & NA & NA & NA & NA & NA & NA & NA & NA & NA \\
\hline F. cf. syhadrensis & India & Karnool & 1 & AB488840 & AB488870 & AB488893 & AB489054 & AB488911 & AB488928 & AB488945 & AB488969 & AB488989 & AB489030 & AB489009 \\
\hline & & & 1 & AB488841 & NA & NA & NA & NA & NA & NA & NA & NA & NA & NA \\
\hline F. cf. syhadrensis & Sri Lanka & Bentota & 1 & AB488839 & AB488869 & AB488892 & AB500237 & AB500244 & AB500250 & AB500223 & AB500230 & NA & AB500260 & AB500267 \\
\hline & & Matale & $1 A$ & AB488839 & NA & NA & NA & NA & NA & NA & NA & NA & NA & NA \\
\hline F. triora & Thailand & Ubon Ratchatani & $2 A$ & AB488820 & AB488860 & AB488883 & AB489046 & AB488905 & AB488922 & AB488939 & AB488963 & AB488982 & AB489022 & AB489003 \\
\hline F. sp. hp2 & Thailand & Bangkok & 1 & AB488821 & $\mathrm{AB} 277281^{\mathrm{a}}$ & AB277299 & NA & $\mathrm{AB} 277307^{\mathrm{a}}$ & $\mathrm{AB} 277321^{\mathrm{a}}$ & NA & AB277338 ${ }^{a}$ & NA & NA & $\mathrm{AB} 277350^{\mathrm{a}}$ \\
\hline & & Mae Hong & $1 A$ & AB488821 & AB277282 ${ }^{\mathrm{a}}$ & AB277299 & NA & $\mathrm{AB} 277307^{\mathrm{a}}$ & $\mathrm{AB} 277321^{\mathrm{a}}$ & NA & $\mathrm{AB} 277335^{\mathrm{a}}$ & NA & NA & $\mathrm{AB} 277349^{\mathrm{a}}$ \\
\hline & & Three Pagoda Pass & 1 & AB488821 & AB277282 & AB277299a & AB500238 & AB277308 & $A B 277323^{a}$ & AB500224 & $A B 277335^{a}$ & AB500254 & AB500261 & AB277349a \\
\hline F. sp. hp3 & Thailand & Pilok & 3 & AB488822 & AB277284 & $\mathrm{AB} 277300^{\mathrm{a}}$ & AB489048 & $\mathrm{AB} 277312^{\mathrm{a}}$ & AB277325 & AB488956 & $\mathrm{AB} 277340^{\mathrm{a}}$ & AB488984 & AB489024 & AB277352 ${ }^{\mathrm{a}}$ \\
\hline F. sp. hp4 & Nepal & Chitwan & $1 A$ & AB488835 & AB488866 & AB488889 & AB500239 & AB500245 & AB500251 & AB500225 & AB500231 & NA & AB500262 & AB500268 \\
\hline F. sp. hp5 & India & Assam & $1 A$ & AB488852 & AB488877 & AB488900 & AB489061 & AB488918 & AB488935 & AB488952 & AB488976 & AB488996 & AB489037 & AB489016 \\
\hline F. sp. hp6 & India & Andaman Island & 1 & AB488850 & AB488876 & AB488899 & AB489060 & AB488917 & AB488934 & AB488951 & AB488975 & AB488995 & AB489036 & AB489015 \\
\hline & & & $1 A$ & AB488851 & NA & NA & NA & NA & NA & NA & NA & NA & NA & NA \\
\hline E. cyanophlyctis & India & Mangalore & $1 A$ & AB488853 & AB488878 & AB488901 & AB489062 & AB488919 & AB488936 & AB488957 & AB488977 & AB488997 & AB489038 & AB489017 \\
\hline H. tigerinus & India & Mangalore & $1 A$ & AB488854 & AB488879 & AB488902 & AB489063 & $A B 277319^{a}$ & $\mathrm{AB} 277331^{\mathrm{a}}$ & AB488958 & AB277345 ${ }^{a}$ & AB488998 & AB489039 & AB277358 ${ }^{a}$ \\
\hline L. laticeps & Malaysia & Kuala Lumpur & 1 & AB4888856 & AB277291 ${ }^{a}$ & AB277306 ${ }^{\mathrm{a}}$ & AB489065 & $\mathrm{AB} 277320^{\mathrm{a}}$ & AB2773332 ${ }^{a}$ & AB488960 & AB277346 ${ }^{a}$ & AB489000 & AB489041 & AB277359 \\
\hline S. dobsoni & India & Bajipe & $1 A$ & AB488855 & AB277290 & $\mathrm{AB} 277305^{\mathrm{a}}$ & AB489064 & AB277318 & $A B 277330^{a}$ & AB488959 & AB277344 ${ }^{a}$ & AB488999 & AB489040 & AB277357 ${ }^{\mathrm{a}}$ \\
\hline O. lima & Malaysia & Kuala Lumpur & $1 A$ & AB488857 & AB488880 & AB488903 & AB489066 & AB488920 & AB488937 & AB488961 & AB488978 & AB489001 & AB489042 & AB489018 \\
\hline O. sp. & Malaysia & Kuala Lumpur & 1 & AB488858 & AB488881 & AB488904 & AB489067 & AB488921 & AB488938 & AB488962 & AB488979 & AB489002 & AB489043 & AB489019 \\
\hline Total & & & 73 & & & & & & & & & & & \\
\hline
\end{tabular}


chondrial (mt) cytochrome b gene (Cytb) sequences from the samples. Cytb, with relatively fast nucleotide substitution rates, has been used as a population- or genus-level molecular marker in dicroglossid frogs, including several Fejervarya taxa (e.g., Dojong et al., 2007b; Alam et al., 2008; Islam et al., 2008b). We also determined nucleotide sequences for parts of $\mathrm{mt} 12 \mathrm{~S}$ and $16 \mathrm{~S}$ ribosomal RNA genes (12S and 16S) from 25 Fejervarya representatives consisting of 15 nominal and 10 unidentified species, for use in molecular species identification and species-genus level molecular phylogenetic analyses. Although the mt COX1 gene is generally used as a "species tag" in DNA barcoding (Hebert et al., 2003a, b; Hebert et al., 2004a, b), Vences et al. (2005a, b) suggested that this gene has several basic problems as a species tag for amphibians. Alternatively, Vences et al. (2005a, b) considered $16 S$ to be a suitable molecular tag for amphibian species, and previous research has demonstrated the utility of this gene in phylogenetic analyses and molecular species identification (Bossuyt et al., 2006; Fouquet et al., 2007; Alam et al., 2008; Vieites et al., 2009). Finally, adding to the $\mathrm{mt}$ genes, we sequenced from the 25 Fejervarya taxa seven additional nuclear genes having relatively slow nucleotide substitution rates (e.g., Hoegg et al., 2004), and tried to elucidate higher level (intra- and intergeneric) relationships for the genus Fejervarya.

\section{MATERIAL AND METHODS}

\section{Specimens}

Sixty-seven Fejervarya specimens from 40 localities in 12 countries were used in this study (Fig. 1). Among them, 37 specimens were identified to species (although our results suggested that some specimens may have been cryptic species or incorrectly identified; see the sections below), and the other 30 specimens could not be identified due to either the small size of the tissue samples or morphological characteristics that failed to match other nominal species (Table 1). We also included six dicroglossid species from closely related genera, i.e., Euphlyctis cyanophlyctis, Hoplobatrachus tigerinus, Sphaerotheca dobsoni, Limnonectes laticeps, Occidozyga lima, and Occidozyga sp.

\section{PCR and sequencing}

Total genomic DNA for PCR was extracted from muscle tissues by using a DNA extraction kit (DNeasy Tissue Kit, QIAGEN) according to the manufacturer's protocol. The amplification primers we used are listed in Table 2. First, part of the Cytb (approximately $650 \mathrm{bp}$ ) was amplified and directly sequenced from all 68 Fejervarya specimens and the six species in other genera. PCR mixtures were prepared with an Ex-Taq Kit (TaKaRa) according to the manufacturer's protocol. DNA sequencing was performed with an automated sequencer ( $\mathrm{ABI} 3100, \mathrm{ABI})$. Next, we amplified and sequenced parts of the 12S and 16S rRNA genes (approx. 400 and $600 \mathrm{bp}$ long, respectively) and seven nuclear genes: brainderived neurotrophic factor ( $B D N F$, approx. $700 \mathrm{bp})$, chemokine receptor 4 (CXCR4, approx. $600 \mathrm{bp}), \mathrm{Na}^{+} / \mathrm{Ca}^{2+}$ exchanger (NCX1, approx. $800 \mathrm{bp}$ ), tyrosinase (Tyr, approx. $700 \mathrm{bp}$ ), rhodopsin (Rhod, approx. 400bp), recombination activating gene 2 (RAG-2, approx. $1.2 \mathrm{kbp}$ ), and 5' and 3' partitions of recombination activating gene 1 (5' and 3' RAG-1, approx. $1 \mathrm{kbp}$ and $900 \mathrm{bp}$ ) from 25 Fejervarya representatives (including 23 specimens with Cytb haplotypes and two F. multistriata specimens) and six other dicroglossids (Table 1). The procedures for amplifying and sequencing these genes were the same as for Cytb. RAG-2 could not be amplified from F. cancrivora, "F. limnocharis" from Orchard Island, $F$. orissaensis, $F$. cf. syhadrensis from Sri Lanka, and F. sp. hp4. The nucleotide sequences determined in this study were deposited in the nucleotide sequence database (accession nos. AB488811-AB489067, $A B 490160$, and $A B 500218-A B 500268$ ) (Table 1). Failing to amplify $R A G-2$ from $F$. cancrivora, " $F$. limnocharis" from Orchard Island, $F$. orissaensis, F. cf. syhadrensis from Sri Lanka, and F. sp. hp4, we treated these unamplified regions as missing data in the following phylogenetic analyses.

\section{Phylogenetic analyses}

The resultant Cytb sequences from the 67 Fejervarya and six other discoglossids were aligned by using ClustalW (Thompson et al., 1994). The resultant alignment matrix contained 535 nucleotide sites. Based on the alignment data, a NJ tree was reconstructed with PAUP4.10b (Swofford, 2002), using the GTR + G + I substitution

Table 2. Primers used in this study for PCR amplification.

\begin{tabular}{|c|c|c|c|}
\hline Gene & Primer name & Sequence (5'-3') & Source \\
\hline \multirow[t]{3}{*}{ Cyt b } & Cyt b_150Fow & ACMGGHYTMTTYYTRGCHATRCAYTA & Kurabayashi and Sumida (2009) \\
\hline & Cyt b Rev1 & CCNGARTGRTAYTTTYCTWTTYGCHTA & This study \\
\hline & Cyt b Rev2 & TTYGCNTAYGCHATYCTNCGMTC & This study \\
\hline \multirow[t]{2}{*}{$12 \mathrm{~S}$ rRNA } & FS01 & AACGCTAAGATGAACCCTAAAAAGTTCT & Sumida et al. (1998) \\
\hline & R16M1 & GGGTATCTAATCCCAGTTTG & Sumida et al. (1998) \\
\hline \multirow[t]{2}{*}{$16 \mathrm{~S}$ rRNA } & F51 & CCCGCCTGTTTACCAAAAACAT & Sumida et al. (2002) \\
\hline & R51 & GGTCTGAACTCAGATCACGTA & Sumida et al. (2002) \\
\hline \multirow[t]{4}{*}{ CXCR4 } & CXCR4-Fow1 & GTNATGGGCTAYCARAARAA & Kotaki et al. (2008) \\
\hline & CXCR4-Fow2 & ATGACWACAAATACAGRYTGCAYCTNTC & Kotaki et al. (2008) \\
\hline & CXCR4-Rev1 & TTGAAYTTGGCNCCSAGGAARGCRTA & Kotaki et al. (2008) \\
\hline & CXCR4-Rev2 & TAATAAGGMARCCARCAGGYRAARAA & Kotaki et al. (2008) \\
\hline \multirow[t]{4}{*}{ NCX1 } & NCX1-Fow1 & GARAAGGARATAACNATYAARAARCC & Kotaki et al. (2008) \\
\hline & NCX1-Fow2 & ATTGAAGTKTGTGGCCAYAAYTT & Kotaki et al. (2008) \\
\hline & NCX1-Rev1 & TTTTCATCTTCYTCAAADATRTCRTC & Kotaki et al. (2008) \\
\hline & NCX1-Rev2 & TCCTTCTGKGTCTCACCWGGYTTRAA & Kotaki et al. (2008) \\
\hline \multirow[t]{5}{*}{ RAG-1 } & RAG1_Ex1_Fow1 & AAATWCTCRGAMTGGAAGTTYAARCT & Kotaki et al. (2008) \\
\hline & RAG1_Ex1_Rev1 & TCACCWYCTTCTTCYTTBTCDGCRAA & Kotaki et al. (2008) \\
\hline & RAG1_Ex1_Fow2 & AACAARGGTGGYMGRCCYCGRCAGCAYCT & This study \\
\hline & RAG1F & AGCTGCAGYCARTACCAYAARATGTA & This study \\
\hline & RAG1_R_mod & AARCACCACTGGCTSTAYACATCCAA & This study \\
\hline \multirow[t]{2}{*}{ RAG-2 } & RAG2-Fow1 & TTWGGNCARAARGGNTGGCC & This study \\
\hline & RAG2-Rev2 & GGNCAYTGGGTNCATKCNCARTGCATGGA & This study \\
\hline \multirow[t]{2}{*}{ Tyr } & Tyr $1 \mathrm{~A}$ & AGGTCCTCTTRAGCAAGGAATG & Bossuyt and Milinkovitch (2000) \\
\hline & Tyr 1E & GAGAAGAAAGAWGCTGGGCTGAG & Bossuyt and Milinkovitch (2000) \\
\hline \multirow[t]{2}{*}{ Rhod } & Rhod $1 \mathrm{~A}$ & ACCATGAACGGAACAGAAGGYCC & Bossuyt and Milinkovitch (2000) \\
\hline & Rhod $1 \mathrm{C}$ & CCAAGGGTAGCGAAGAARCCTTC & Bossuyt and Milinkovitch (2000) \\
\hline \multirow[t]{2}{*}{ BDNF } & BDNF-Fow1 & ATGACCATCCTTTTCSTKACNATG & This study \\
\hline & BDNF-Rev1 & ACNATHAARAGGGGMAGATAG & This study \\
\hline
\end{tabular}


model suggested by the Akaike information criterion (AIC) implemented in MODELTEST ver. 3.06 (Posada and Crandall, 1998). Hoplobatrachus tigerinus was used as the outgroup in this analysis.

Alignment data were also prepared for two additional mt genes and eight partitions of seven nuclear genes for the 25 Fejervarya representatives with clearly distinct haplotypes and the six other dicroglossids. For these genes, the alignments were revised by using GBlock 0.91b (Castresana, 2000) with the default settings to exclude gaps and ambiguous sites. One concatenated alignment for the three $\mathrm{mt}$ and seven nuclear genes (total $6364 \mathrm{bp}$ ) was prepared. Based on the concatenated data, phylogenetic analyses were performed by maximum-likelihood (ML) and maximum-parsimony (MP) with PAUP 4.10b (Swofford, 2002). In addition, Bayesian inference (BI) analyses were performed with MrBayes ver. 3.0b4 (Huelsenbeck and Ronquist, 2001). The partition homology test (Farris et al. 1995) rejected the concordance of nucleotide substitution patterns among three $\mathrm{mt}$ and seven nuclear genes. Therefore, the data set was treated as different partitions in the $\mathrm{BI}$ analyses. The analyses were performed by setting the number of Markov chain Monte Carlo (MCMC) generations at two million, setting the sampling frequency as 10 , and discarding the first 200,000 generations. For the $\mathrm{ML}$ and $\mathrm{BI}$ analyses, best-fit substitution models were chosen by AIC as follows: GTR + I + G for the concatenated nuclear genes data (in $M L$ ); HKY for the Rhod partition; GTR for the Cytb, 16S, and 3' RAG-1 partitions; SYM for the Tyr partition; TIM for the 5' RAG-1 partition; and TrN for the 12S rRNA, BDNF, CXCR4, NCX1, and RAG-2 partitions (in $\mathrm{BI}$ ). Two Occidozyga species were used as the outgroups in these analyses. The reliabilities of the resultant phylogenetic trees were evaluated with the bootstrap proportion (BP). Bootstrap values were calculated by analysis of 300 and 1000 pseudoreplicates in the ML and MP analyses, respectively. Statistical support for the resultant $\mathrm{BI}$ trees was determined with Bayesian posterior probability (BPP). Topologies of resultant trees and several alternative hypotheses were compared by resampling the sitewise log-likelihood (RELL), i.e., the Kishino-Hasegawa $(\mathrm{KH}$; Kishino and Hasegawa, 1989) and ShimodairaHasegawa (SH; Shimodaira and Hasegawa, 1999) tests, using PAUP. RELL was conducted with 10,000 resamplings.

\section{RESULTS AND DISCUS- SION}

Cytb haplotypes and phy-
logeny of Fejervarya spe-
cies based on mt gene
data ence of part of the Cytb gene (approx. $650 \mathrm{bp}$ ) was determined for the 67 Fejervarya specimens. Twentythree major haplotypes were observed among the resultant sequences. The $\mathrm{NJ}$ tree based on the Cytb data recovered 23 clades of these major haplotypes (Clades 1-23 in Fig. 2). As in previ- ous studies, the clades were divided largely into South- and Southeast-Asian groups (Kurabayashi et al., 2005; Sumida et al., 2007; Kotaki et al., 2008). Among the 23 major haplotype groups, 14 clearly corresponded to nominal Fejervarya species (i.e., cancrivora, caperata, granosa, greenii, iskandari, kirtisinghei, kudremukhensis, limnocharis, mudduraja, orissaensis, pierreri, rufescence, sakishimaensis, and triora). Five haplotypes from unidentified individuals ( $F$. sp. hp2 from Thailand, $F$. sp. hp3 from Pilok in Thailand, $F$. sp. hp4 from Nepal, F. sp. hp5 from India, and $F$. sp. hp6 from the Andaman Islands) had no affinity to the haplotypes of the nominal species (Fig. 2) and no corresponding sequences in DNA databases (data not shown). The specimens of " $F$. cf. syhadrensis" showed two distinct haplotypes (Sri Lanka and Western Ghats, India). While both of the $F$. cf. syhadrensis haplotypes belonged to the South-Asian group, the Sri Lankan group had a close affinity to the $F$. granosa clade, and the Indian group was a sister group to the $F$. greenii $+F$. kirtisinghei clade. The F. multistriata specimens (from China and Taiwan) were included in the $F$. limnocharis clade (Clade 18 in Fig. 2). In this analysis, we also included 14 other unidentified Fejervarya samples (two from Cambodia, three from Laos, six from Thailand, and three from Vietnam). The haplotypes from these samples were very similar to those of $F$. limnocharis, and they were embedded within the $F$. limnocharis clade in the $\mathrm{NJ}$ tree (Clade 18). Nucleotide sequence divergences for Cytb within the F. limnocharis clade (including F. multistriata haplo-

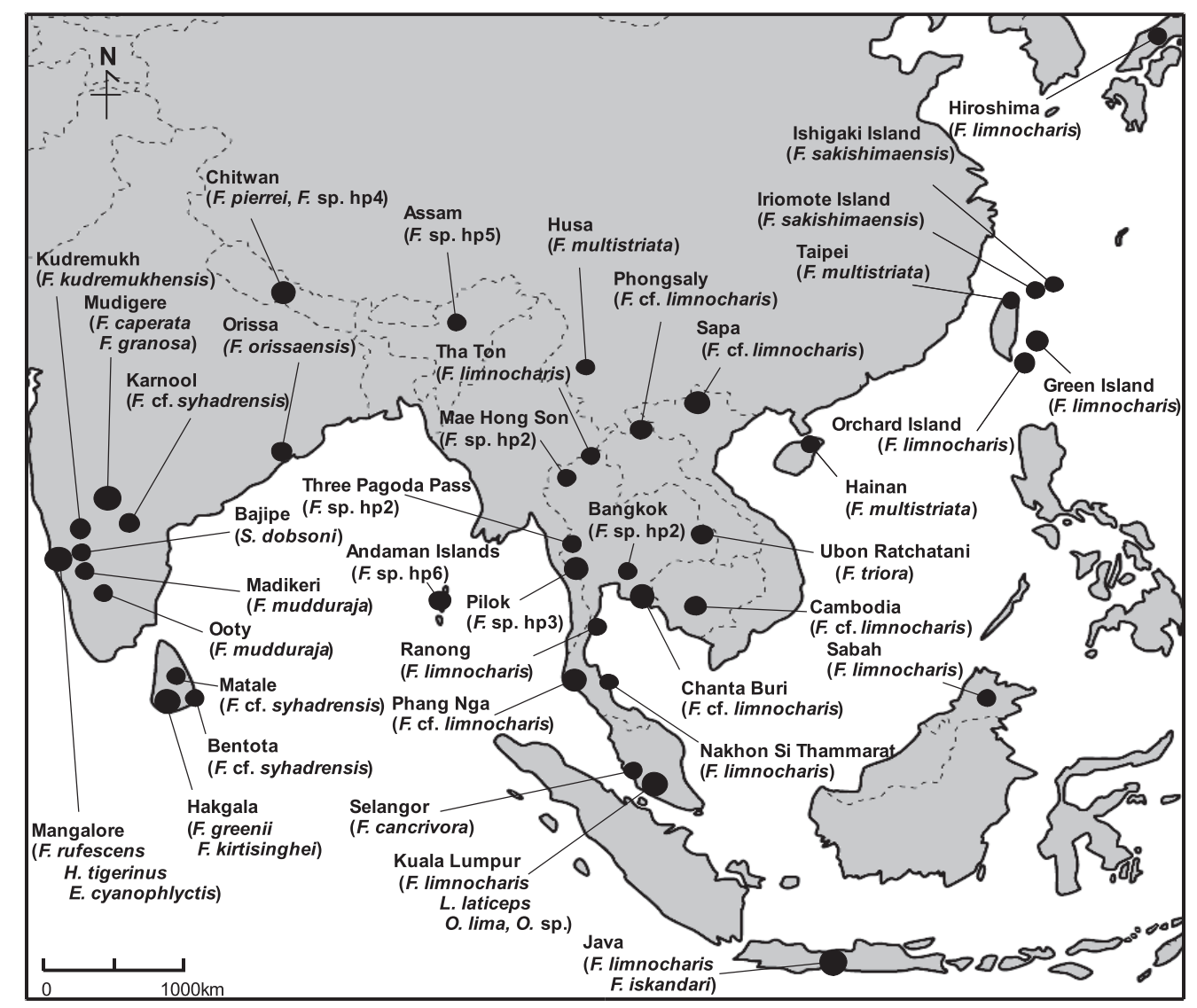

Fig. 1. Map showing collecting localities for frogs included in this study. The size of the circles is proportional to the number of individuals collected at a locality. 


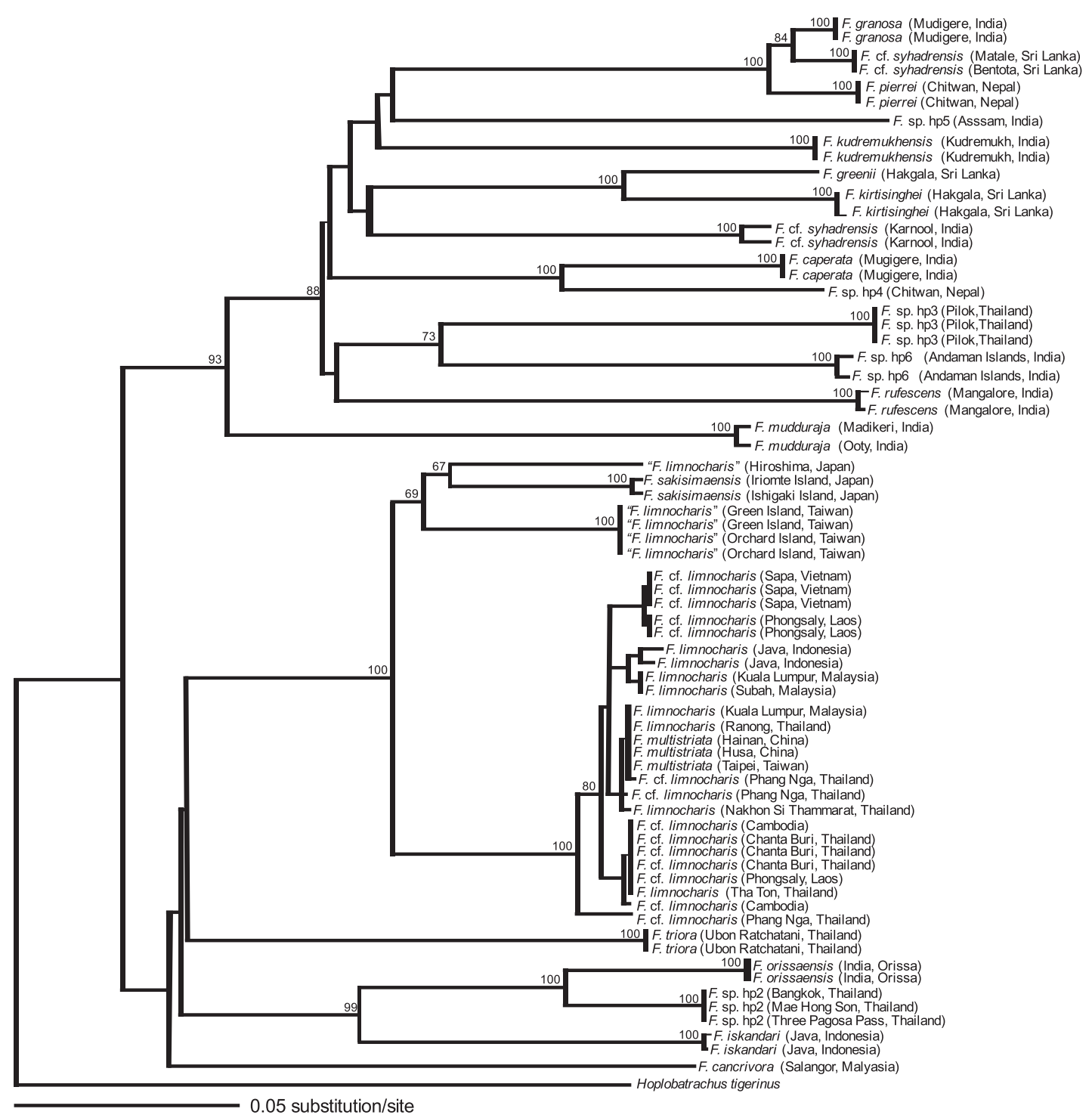

Fig. 2. Neighbor-Joining tree based on 532 bp of the mitochondrial Cytb gene sequenced from 67 frogs. The tree was reconstructed by using PAUP with the heuristic search option and the GTR $+I(=0.50)+G(=1.41)$ substitution model, suggested by Modeltest. NJ Bootstrap values are shown near nodes.

types) were very low (1.0\%), and this clade included the $F$. limnocharis specimens from the type locality (Java, Indonesia). On the other hand, the specimens from Japan (Hiroshima) and Taiwan (Green and Orchard Islands), traditionally regarded as $F$. limnocharis, comprised clades distinct from the F. limnocharis clade (Clades 15 and 17, respectively).

Based on the results of the Cytb haplotype analysis, we selected 25 Fejervarya individuals (23 major Cytb haplotype groups plus two F. multistriata) and the six other dicroglossids as the representatives of each haplotype group, and $12 S$ and $16 S$ were sequenced from these 31 frogs. Based on the combined mt gene data, we carried out MP, $\mathrm{ML}$, and $\mathrm{BI}$ analyses. The resultant $\mathrm{ML}$ tree and nodal support values from these analyses (BPs and BPP) are shown in Supplemental Fig. S1. The resultant trees had basically the same topology as the Cytb NJ tree, except for the positions of $F$. cf. syhadrensis and Limnonectes (the former was the sister group to Clade $9+10$ in all analyses, and the lat- ter grouped with Southeast-Asian Fejervarya in the MP and BI trees).

Phylogenetic relationships of Fejervarya taxa and closely related genera based on the concatenated data

To elucidate phylogenetic relationships in more detail at both the intra- and inter-generic levels, we additionally determined nucleotide sequences for eight parts of seven nuclear genes (BDNF, CXCR4, NCX1, the 5' and 3' portions of RAG1, RAG-2, Rhod, and Tyr) from the above 25 Fejervarya representatives and six species in closely related genera (Table 1). Based on the concatenated alignment (three mt genes and seven nuclear genes; total $6364 \mathrm{bp}$ ), we carried out MP, $\mathrm{ML}$ and $\mathrm{BI}$ analyses. Fig. 3 shows the resultant $\mathrm{ML}$ tree (with $\mathrm{BP}$ and BPP values for all analyses); the MP and $\mathrm{BI}$ analyses recovered the same topology.

In the concatenated tree, the interspecific relationships differed somewhat from those in the Cytb NJ tree. The incongru- 


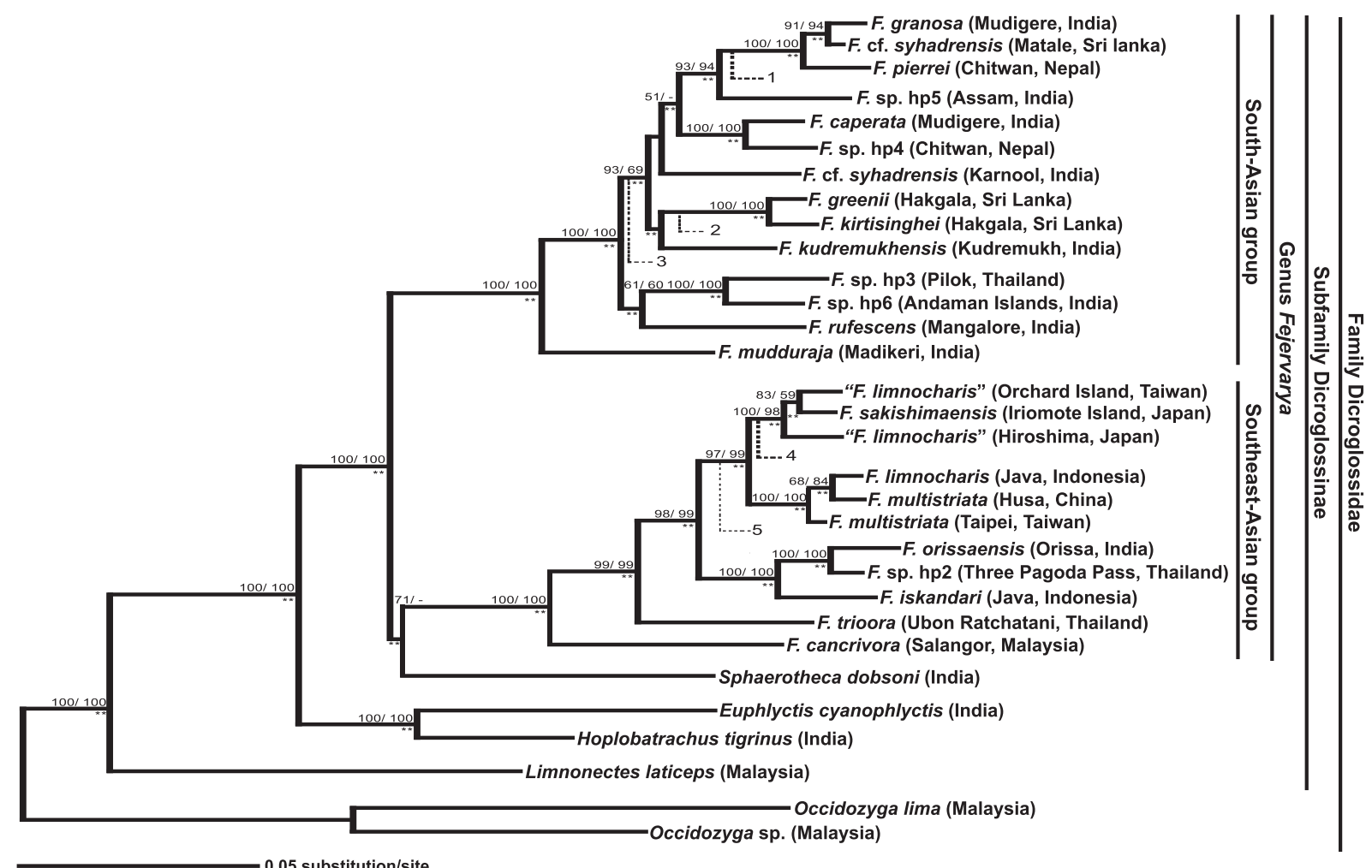

Fig. 3. Maximum-likelihood tree for 31 frogs based on $6364 \mathrm{bp}$ of mitochondrial (Cytb, 12S, and 16S) and nuclear genes (BDNF, CXCR4, NCX1, RAG-1, RAG-2, Rhod, and Tyr). The tree was reconstructed by using PAUP with the heuristic search option and the GTR + I (= 0.48$)+$ $\mathrm{G}(=0.54)$ substitution model, suggested by Modeltest. ML/MP bootstrap values are shown near nodes. Asterisks below branches indicate the Bayesian posterior probability: *, greater than $95 \%$; ${ }^{* *}$, greater than $99 \%$. Locality and country are shown in parenthesis. The dashed lines correspond to branches in the Cytb NJ tree: $1, F$. kudremukhensis; 2, F. cf. syhadrensis from Karnool, India; 3, the F. caperata $+F$. sp. hp4 clade; 4, "F. limnocharis" from Orchard Island, Taiwan; 5, F. triora).

Table 3. Comparison of log-likelihood scores ( $\mathrm{KH}$ and SH tests) among alternative tree topologies resulting from analyses of three mitochondrial and seven nuclear genes.

\begin{tabular}{|c|c|c|c|c|c|}
\hline \multirow{2}{*}{ Tree topology } & \multirow{2}{*}{ Method } & \multirow{2}{*}{$-\ln \mathrm{L}$} & \multirow{2}{*}{-In $\mathrm{L}$ difference } & \multicolumn{2}{|c|}{$P$-value } \\
\hline & & & & $\mathrm{KH}$ & $\mathrm{SH}$ \\
\hline (L. laticeps,((H. tigerinus, E. cyanophlyctis),(South Asia,(Southeast Asia, S. dobsoni $)))$ & ML, MP, BI based on all combined & 35067.68284 & best tree & - & - \\
\hline$(($ H. tigerinus, E. cyanophlyctis),(S. dobsoni,(L. laticeps,( Southeast Asia, South Asia)))) & ML based on mt combined & 35224.82345 & 157.14061 & $0.0000^{*}$ & $0.0000^{*}$ \\
\hline$(($ H. tigerinus, E. cyanophlyctis),(S. dobsoni,( South Asia,( Southeast Asia, L. laticeps $))))$ & MP, BI besed on mt combined & 35224.61549 & 156.93265 & $0.0000^{*}$ & $0.0000^{*}$ \\
\hline (L. laticeps,(Southeast Asia,(S. dobsoni,(South Asia,(H. tigerinus, E. cyanophlyctis))))) & mt and nuclear combined (Frost et al., 2006) & 35142.31901 & 74.63617 & $0.0000^{*}$ & $0.0000^{*}$ \\
\hline (L. laticeps,(S. dobsoni,(South Asia,(Southeast Asia,(H. tigerinus, E. cyanophlyctis))))) & ML based on mt combined (Kotaki et al., 2008) & 35140.50305 & 72.82022 & $0.0001^{*}$ & $0.0003^{*}$ \\
\hline (L. laticeps,((H. tigerinus, E. cyanophlyctis),(Southeast Asia,(South Asia, S. dobsoni $)))$ & $\begin{array}{l}\text { MP, BI based on nuclear combined (Kotaki et al., } \\
\text { 2008) }\end{array}$ & 35069.25654 & 1.57371 & 0.4674 & 0.7424 \\
\hline (L. laticeps,(S. dobsoni,((H. tigerinus, E. cyanophlyctis),(Southeast Asia, South Asia)))) & - & 35137.63825 & 69.95541 & $0.0000^{*}$ & $0.0001^{*}$ \\
\hline (L. laticeps,((H. tigerinus, E. cyanophlyctis),(S. dobsoni,(Southeast Asia, South Asia $))))$ & - & 35068.98452 & 1.30169 & 0.5795 & 0.7688 \\
\hline
\end{tabular}

*Values were not significant (significance level, $p<0.05$ ) among any of the topologies compared.

ent relationships were as follows: the positions of $F$. kudremukhensis (1 in Fig. 3), F. cf. syhadrensis from Karnool, India (2 in Fig. 3), and the F. caperata + F. sp. hp4 clade (3 in Fig. 3 ) in the South-Asian group; and the placements of " $F$. limnocharis" from Orchard Island, Taiwan (4 in Fig. 3) and $F$. triora (5 in Fig. 3) in the South-Asian group. Although the nodal support values in the concatenated tree were far higher than those in the Cytb $\mathrm{NJ}$ tree, those of the incongruent nodes were not so high, with the exception of the position of $F$. triora (Fig. 3). We tested these incongruent relationships between the Cytb and concatenated data using $\mathrm{KH}$ and $\mathrm{SH}$ tests. These tests rejected the position of $F$. triora suggested by the
Cytb data (clade $18+19$ in Fig. 2$)(p>0.05)$. The other four incongruent relationships, however, were not rejected.

According to Frost et al. (2006), the genus Fejervarya may be a paraphyletic rather than monophyletic group with respect to some other dicroglossid genera (e.g., Euphlyctis, Hoplobatrachus, Nannophrys, and Sphaerotheca). Similarly, our concatenated analyses recovered a clade containing the Southeast-Asian Fejervarya group and another genus, Sphaerotheca (ML/MP BPs $=71 /-$; BPP $=100$ ). Thus, our data suggest paraphyly for Fejervarya (Fig. 3). The $\mathrm{MP}$ and $\mathrm{BI}$ trees from the mt gene data suggested paraphyly for this genus, but with an alternative topology (the 
Southeast-Asian group + Limnonectes). Our previous analyses also suggested paraphyly for this genus with yet other topologies (South-Asian Fejervarya + Hoplobatrachus by $\mathrm{ML}$ analysis based on the $\mathrm{mt}$ gene data, and South-Asian Fejervarya + Sphaerotheca by MP and BI analyses based on the nuclear gene data). We therefore tested the eight alternative topologies with three monophyletic, four paraphyletic, and one polyphyletic hypotheses for this genus by $\mathrm{KH}$ and
$\mathrm{SH}$ tests based on the concatenated data (Table 3). Five of the eight alternative topologies were rejected $(p>0.05)$, but three hypotheses were not rejected. These non-rejected hypothetical topologies were: 1) Southeast-Asian Fejervarya + Sphaerotheca (= Fig. 3), 2) South-Asian Fejervarya + Sphaerotheca, and 3) monophyly of Fejervarya.

Given the congruent results from both the mt and concatenated data and the high nodal support in the combined

Table 4. Nucleotide sequence divergences between taxa with different degrees of reproduction isolation and between nominal species, for three $\mathrm{mt}$ and seven nuclear genes. Values inside parentheses indicate average sequence divergence.

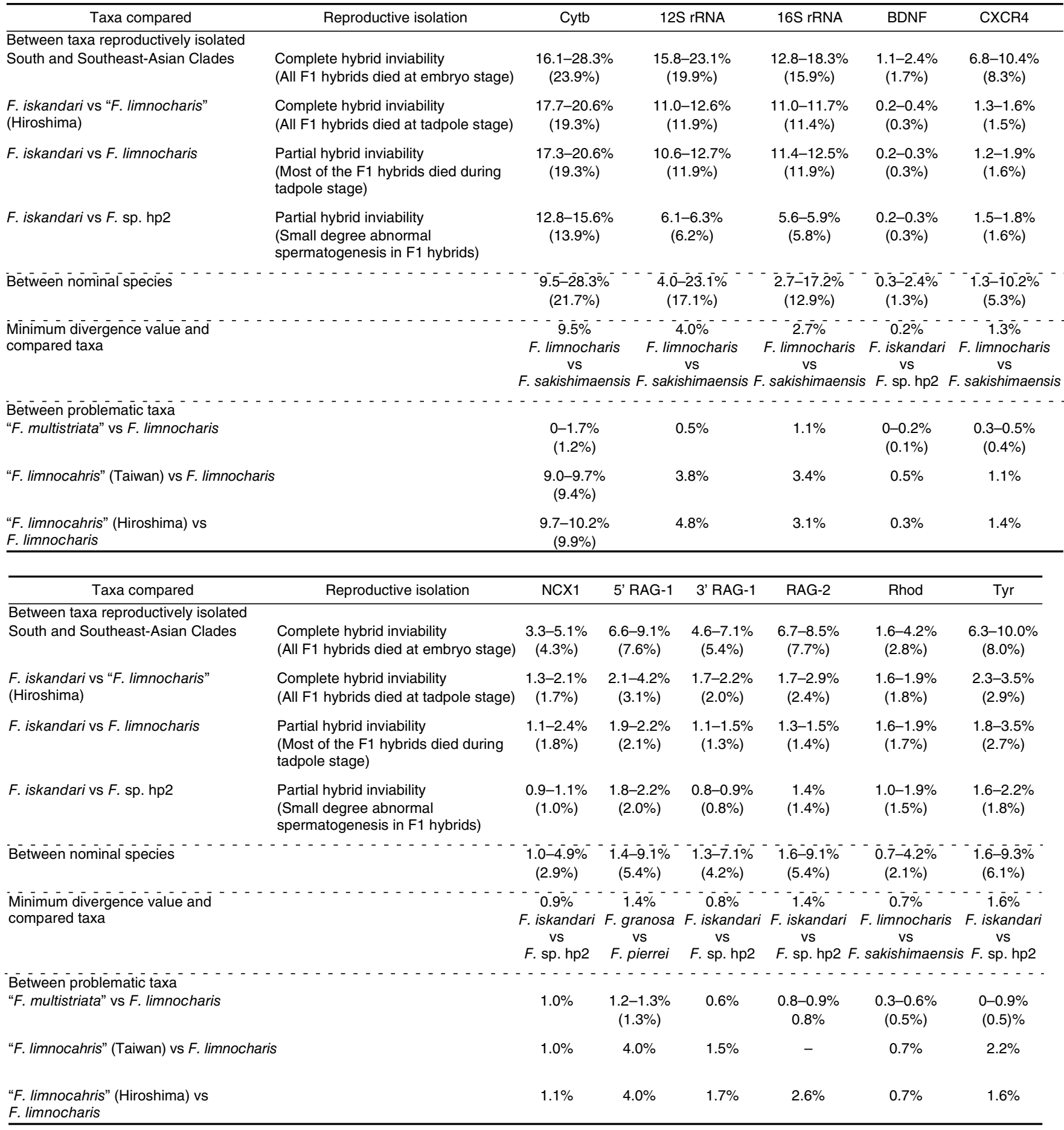


analyses, our combined analyses well elucidated the intrageneric relationships of the genus Fejervarya in most cases. However, there remained four ambiguous intra-generic relationships that were not rejected by statistical tests. We also failed to elucidate the inter-generic relationships, although we condensed this problem to only three alternative hypotheses. In this study, we used relatively long sequence data from multiple loci. Thus, extensive taxon sampling and/or non-sequence-based approaches, i.e., cladistic analyses using retroposon loci (e.g., Okada et al., 2003) or mt gene order information (e.g., Kurabayashi et al., 2008), might be effective in solving the remaining problems.

\section{Taxonomic implications for the unidentified species found in this study}

Based on the resultant trees (Figs. 2, 3), some taxa with problematic taxonomic affiliation were brought out (i.e., $F$. "limnocharis" from Taiwan and Japan, F. "multistriata", and $F$. cf. syhadrensis; see below). Species identification with nucleotide divergence data has been suggested as an effective procedure for extrapolating the detailed taxonomic status of these problematic taxa (e.g., Sumida et al., 2007; Djong et al., 2007b; Alam et al., 2008). In anurans, $16 S$ has been considered a usable marker for determining taxonomic affiliations and detecting unconfirmed candidate (i.e., cryptic) species. Data suggest that a $3 \%$ divergence in this gene is a species threshold in several different frog taxa (hylids from the Amazonia-Guianas region and all Malagasy frogs, including hyperoliids, microhylids, and mantellids) (Fouquet et al., 2007; Vieites et al., 2009). In our studies, the minimum 165 divergence among nominal Fejervarya species is roughly $3 \% \quad(=2.7 \%$ between $F$. limnocharis and $F$. sakishimaensis) (Table 4). This confirms the adequacy of this species threshold criterion in Fejervarya. We also compared the nucleotide divergences of the other genes among the nominal species and between taxa whose reproductive isolation had been confirmed by artificial crossing experiments (Sumida et al., 2007) (Table 4). Genetic divergences were highly variable among genes, and the genetic divergence of each gene tended to be correlated with both the degree of reproductive isolation and relative phylogenetic positions in the resultant tree. Minimum divergence values occurred among sister nominal species for all genes (Table 4 ; Figs. 2, 3), and four of these pairs were weakly reproductively isolated (for BDNF, NCX-1, RAG-2, and Tyr). These minimum divergence values reflected reproductive isolation levels and/or the resultant phylogeny, and can be regarded as species thresholds for this frog group. The unduly low minimum vales found for the nuclear genes $(0.3 \%$ for $B D N F$ to $1.6 \%$ for $T y r$ ) are somewhat difficult to use as a basis for species definition. Moreover, few of the genes studied here (excluding 16S) have been examined to confirm their suitability for use in other frog taxa. Thus, we mainly used the minimum 165 divergence value $(>3 \%)$ to evaluate the taxonomic status of problematic taxa.

Fejervarya multistriata (Hallowell) 1861 is one of the problematic taxa. This species was described from Hong Kong, China. In this study, rather than using topotypic $F$. multistriata specimens, we used individuals from Hainan and Husa, China (approx. 400 and 1500 km from Hong Kong, respectively) and Taipei (mainland), regions from where the species has been reported (Frost, 2009). The $16 S$ sequence divergence between topotypic $F$. limnocharis and " $F$. multistriata" individuals was only $1.1 \%$, which was much less than the proposed species threshold value (> $3 \%)$. Furthermore, in the concatenated tree (Fig. 3), the topotypic $F$. limnocharis was nested in the "F. multistriata" clade (i.e., " $F$. multistriata" individuals were paraphyletic with respect to $F$. limnocharis). These results strongly suggest that the $F$. limnocharis and the " $F$. multistriata" specimens are conspecific. Djong et al. (2007b) contended that the name " $F$. multistriata" applies to the populations in China formerly referred to $F$. limnocharis. Our results may support this contention and may suggest that the name " $F$. multistriata" is a junior synonym of $F$. limnocharis.

"Fejervarya limnocharis" from the Japan mainland (Hiroshima) and eastern Taiwan (Orchard and Green Islands) populations has been problematic. Sumida et al. (2007) suggested that the Japan mainland populations be regarded as a species distinct from the real $F$. limnocharis. Matsui et al. (2007) pointed out that the eastern Taiwan (+ eastern China) populations are possibly conspecific with $F$. sakishimaensis. In this study, neither " $F$. limnocharis" specimens from the Japan mainland nor " $F$. limnocharis" specimens from eastern Taiwan formed a clade with the topotypic $F$. limnocharis. Furthermore, for many genes, including $16 \mathrm{~S}$ $(>3 \%$ ), the nucleotide divergences between the topotypic $F$. limnocharis and these specimens were equal to or higher than the minimum divergence values among nominal species (Table 4). These results seem to indicate that both the Japan mainland and eastern Taiwan populations are species distinct from $F$. limnocharis, and they seem to support the view of Sumida et al. (2007). The phylogenetic relationships we detected suggest that these populations have a close affinity with F. sakishimaensis. However, the $16 S$ sequence divergences among these taxa were nearly equal to the species threshold values $(3.3 \%$ between the Japan mainland and eastern Taiwan, $2.8 \%$ between the Japan mainland and $F$. sakishimaensis, and $2.7 \%$ between eastern Taiwan and $F$. sakishimaensis). Thus, two possibilities can now be considered for these taxa: 1) the Japan mainland and eastern Taiwan populations are conspecific with $F$. sakishimaensis (the assignment of Matsui et al. [2007]), or 2) all three taxa are distinct species.

Fejervarya syhadrensis, a species characterized by small body size, relatively short legs, finger morphology, and the length of hindlimbs (see Kuramoto et al., 2007; Amphibia Web: http://amphibiaweb.org/), has been considered to have a relatively wide distribution range (from Pakistan to Bangladesh). In this study, we used $F$. syhadrensis-like specimens from two different populations (Sri Lanka and the Western Ghats, India). Based on the resultant phylogeny (Fig. 3) and the 16S sequence divergence between the populations $(11.5 \%)$, the $F$. syhadrensis-like specimens from these populations are clearly distinct species.

The $16 S$ sequence from our $F$. syhadrensis-like specimen from the Western Ghats failed to hit any of the other Fejervarya $16 S$ data deposited in the DNA databases, while that of our Sri Lanka specimen was almost identical a sequence from " $F$. syhadrensis" from Sri Lanka (Accession No. AY141843). This Sri Lanka F. syhadrensis record is doubtful, as the distribution of $F$. syhadrensis in Sri Lanka is 
unclear (Frost, 2009). Furthermore, 18 other "F. syhadrensis" $16 S$ sequences have been deposited in the DNA databases. Among them, five sequences were typical for $F$. caperata (AY882951, AY841752, AY882956, AY841755, and AY841753), while the other 13 showed intraspecific levels of nucleotide divergence compared to the sequences of our $F$. cf. syhadrensis and the above " $F$. syhadrensis" from Sri Lanka (mainly less than $2.0 \%$, but $2.8 \%$ between AY84175 and AY841750, and 3.0\% between AY84175 and the Sri Lanka samples). According to Frost (2009), the type locality is the Poona district in India. Before analyzing the type specimen or topotypic specimens of $F$. syhadrensis, it is difficult to specify which data correspond to the real $F$. syhadrensis, or to assert that none of the previous data correspond to this species.

As in the case with $F$. syhadrensis, some $F$. cancrivora sequences in the DNA databases seem to be problematic. According to a recent study by Kurniawan et al. (2009), " $F$. cancrivora" populations are morphologically (and ecologically) divided into three distinct groups (the large, mangrove, and Pelabuhan ratu/Sulawesi types); genetic divergences among these groups clearly correspond to the level of distinct species, and the large type corresponds to topotypic $F$. cancrivora. The $F$. cancrivora specimen we included corresponds to the large type and thus can be regarded as real F. cancrivora.

Several unidentified Fejervarya samples (F. sp. hp2hp6; only tissue samples were available) were included in this study. None of the nucleotide sequences from these samples hit any sequences from other Fejervarya species deposited in the DNA databases. One unidentified sample (F. sp. hp4) was from Nepal, a region where four Fejervarya species have been reported (Schleich and Kästle, 2002). One of these four species is $F$. pierreri as used in this study, and the other three are F. nepalensis, F. syhadrensis, and $F$. teraiensis. The F. sp. hp4 specimen may correspond to one of the latter three species. Two of the unidentified haplotype groups ( $F$. sp. hp2 and hp3) found in this study were from Thailand. According to our previous studies (Sumida et al., 2007; Kotaki et al., 2008), F. sp. hp3 from Pilok, Thailand may be an undescribed species, and $F$. sp. hp2 may be the same species as $F$. orissaensis or an undescribed species. On the Andaman Islands, only two Fejervarya species ( $F$. andamanensis and $F$. cancrivora) have been found (Frost, 2009 ), and in the current study we used the real $F$. cancrivora. Thus, one unidentified sample, $F$. sp. hp6 from Andaman Island, India, might correspond to $F$. andamanensis.

\section{CONCLUSION}

Our phylogenetic trees are the most comprehensive to date for Fejervarya species. They provide relatively highresolution of interspecific relationships and support paraphyly for this genus. Yet despite the relatively abundant molecular data used in this study, several incongruent or ambiguous relationships remain in these trees. To solve these problems, further taxon sampling or a novel approach using different types of molecular makers (e.g., mt gene arrangement or SINEs) will be necessary. We also confirmed the utility of the molecular data, especially $16 \mathrm{~S}$ sequences, for species definition. The sequence data provided here are likely to serve as a useful guide for elucidat- ing the taxonomic problems in this frog taxon.

\section{ACKNOWLEDGMENTS}

We are grateful to Emeritus Prof. M. Nishioka and Prof. A. Kashiwagi of Hiroshima University, Japan; Prof. H. Ota of the University of the Ryukyus, Japan; Prof. T. Hikida of Kyoto University, Japan; Prof. M. Vences, University of Braunschweig, Germany; Prof. A. Dubois and Prof. A. Ohler, Museum National d' Histoire Naturelle, France; Prof. R. F. Inger and Dr. B. Stuart, Field Museum, USA; Prof. Y.-C. Kan and Dr. C.-S. Wu, Tunghai University, Taiwan; Dr. M. Tandon, National DNA Center, India; Prof. S. K. Dutta, North Orissa University, India; and Prof. V. K. Kashyap, National Institute of Biologicals, India, for their kindness in collecting and supplying specimens for DNA analyses. We also acknowledge Prof. C. Wanichanon, Mahidol University, Thailand; Prof. S. H. Joshy of St. Aloysius College, India; Prof. Yong H. Sen and Dr. Daicus M. Belabut, University of Malaya, Malaysia; Prof. P. Eamsobhana, Mahidol University, Thailand; Prof. De Silva Anslem, University of Peradeniya, Sri Lanka; and Dr. W. Khonsue, Chulalongkorn University, Thailand, for their kind and valuable help and support in collecting specimens from the field. This work was supported by Grant-in-Aids for Scientific Research (C) (Nos. 17570082 and 20510216) to M. Sumida from the Ministry of Education, Culture, Sports, Science and Technology, Japan. Our molecular work was performed with the gracious cooperation of the Analysis Center of Life Science and the Natural Science Center for Basic Research and Development, Hiroshima University.

\section{REFERENCES}

Alam MS, Igawa T, Khan MMR, Islam MM, Kuramoto M, Matsui M, Kurabayashi A, Sumida M (2008) Genetic divergence and evolutionary relationships in six species of genera Hoplobatrachus and Euphlyctis (Amphibia: Anura) from Bangladesh and other Asian countries revealed by mitochondrial gene sequences. Mol Phylogenet Evol 48: 515-527

Bossuyt F, Milinkovitch MC (2000) Convergent adaptive radiations in Madagascan and Asian ranid frogs reveal covariation between larval and adult traits. Proc Natl Acad Sci USA 97: 6585-6590

Bossuyt F, Brown RM, Hillis DM, Cannatella DC, Milinkovitch MC (2006) Phylogeney and biogeography of a cosmopolitan frog radiation: Late Cretaceous diversification resulted in continentscale endemism in the family Ranidae. Syst Biol 55: 579-594

Castresana J (2000) Selection of conserved blocks from multiple alignments for their use in phylogenetic analysis. Mol Biol Evol 17: 540-552

Djong TH, Islam MM, Nishioka M, Matsui M, Ota H, et al. (2007a) Genetic relationships and reproductive isolation mechanism among the Fejervarya limnocharis complex from Indonesia (Java) and other Asian countries. Zool Sci 24: 360-375

Djong TH, Matsui M, Kuramoto M, Daicus MB, Yong HS, Nishioka M, Sumida M (2007b) Morphological divergence, reproductive isolation mechanism, and molecular phylogenetic relationships among Indonesia, Malaysia, and Japan populations of the Fejervarya limnocharis complex (Anura, Ranidae). Zool Sci 24: 1197-1212

Dubois A (1975) Un nouveau complexe d'especes jumelles distinguees par le chant: les grenouilles du Nepal voisines de Rana limnocharis Boie (Amphibiens: Anoures). C R Acad Sci D 281: 1717-1720

Farris JS, Kallersjo M, Kluge AG, Bult C (1995) Testing significance of incongruence. Cladistics 10: 315-319

Fouquet A, Gilles A, Vences M, Marty C, Blanc M, Gemmell NJ (2007) Underestimation of species richness in Neotropical frogs revealed by mtDNA analyses. PLoS One 2: e1109

Frost DR (1985) Amphibian Species of the World. Allen Press, 
Lawrence

Frost DR (2009) Amphibian Species of the World: An Online Reference, V3.0. Electronic database available at http:// research.amnh.org/herpetology/amphibia/index.html

Frost DR, Grant T, Faivovich J, Bain R, Haas A, et al. (2006) The amphibian tree of life. Bull Am Mus Nat Hist 297: 11-291

Hallowell E (1861) Report upon the Reptilia of North Pacific exploring expedition, under command of Capt. John Rogers, USN. Proc Acad Nat Sci Philadelphia 1860: 480-510

Hebert PDN, Cywinska A, Ball SL, de Waard JR (2003a) Biological identification through DNA barcodes. Proc R Soc Lond B 270: 313-321

Hebert PDN, Ratnasingham S, de Waard JR (2003b) Barcoding animal life: cytochrome $c$ oxidase subunit 1 divergences among closely related species. Proc R Soc Lond B (Suppl) 270: S96S99

Hebert PDN, Penton EH, Burns JM, Janzen DH, Hallwachs W (2004a) Ten species in one: DNA barcoding reveals cryptic species in the Neotropical skipper butterfly Astraptes fulgerator. Proc Natl Acad Sci USA 101: 14812-14817

Hebert PDN, Stoekle MY, Zemlak TS, Francis CM (2004b) Identification of birds through CO1 DNA barcodes. Phil Trans R Soc Lond B 359: 669-679

Hoegg S, Vences M, Brinkmann H, Meyer A (2004) Phylogeny and comparative substitution rates of frogs inferred from sequences of three nuclear genes. Mol Biol Evol 21: 1188-1200

Huelsenbeck JR, Ronquist F (2001) MRBAYES: Bayesian inference of phylogenetic trees. Bioinformatics 17: 754

Iskandar DT (1998) The Amphibians of Java and Bali. LIPI, Yayasan Kehati, Bogor

Islam MM, Khan MMR, Djong TH, Alam MS, Sumida M (2008a) Genetic differentiation of the Fejervarya limnocharis complex from Bangladesh and other Asian countries elucidate by allozyme analyses. Zool Sci 25: 261-272

Islam MM, Kurose N, Khan MMR, Nishizawa T, Kuramoto M, Alam MS, Hasan M, Kurniawan N, Nishioka M, Sumida M (2008b) Genetic divergence and reproductive isolation in the genus Fejervarya (Amphibia: Anura) from Bangladesh inferred from morphological observations, crossing experiments, and molecular analyses. Zool Sci 25: 1084-1105

Kishino H, Hasegawa M (1989) Evaluation of the maximum likelihood estimate of the evolutionary tree topologies from DNA sequence data, and the branching order in Hominoidea. $\mathrm{J} \mathrm{Mol}$ Evol 29: 170-179

Kotaki M, Kurabayashi A, Matsui M, Khonsue W, Djong TH, Tandon M, Sumida M (2008) Genetic divergences and phylogenetic relationships among the Fejervarya limnocharis complex in Thailand and neighboring countries revealed by mitochondrial and nuclear genes. Zool Sci 25: 381-390

Kurabayashi A, Sumida M (2009) PCR primers for the neobatrachian mitochondrial genome. Curr Herpetol 28: 1-11

Kurabayashi A, Kuramoto M, Joshy H, Sumida M (2005) Molecular phylogeny of the ranid frogs from the Southwest India based on the mitochondrial ribosomal RNA gene sequences. Zool Sci 22: 525-534

Kurabayashi A, Sumida M, Yonekawa H, Glaw F, Vences M, Hasegawa M (2008) Phylogeny, recombination, and mechanisms of stepwise mitochondrial genome reorganization in mantellid frogs from Madagascar. Mol Biol Evol 25: 874-891

Kuramoto M, Joshy SH (2001) Advertisement call structures of frogs from southwestern India, with some ecological and taxonomic notes. Curr Herpetol 20: 85-95

Kuramoto M, Joshy SH, Kurabayashi A, Sumida M (2007) The genus Fejervarya (Anura: Ranidae) in central western Ghats, India, with description of four new cryptic species. Curr Herpetol 26: 81-105
Kurniawan N, Islam MM, Djong TH, Igawa T, Daicus MB, et al. (2009) Genetic divergence and evolutionary relationship in Fejervarya cancrivora from Indonesia and other Asian countries inferred from allozyme and mtDNA sequence analyses. Zool Sci 26: 222-233

Matsui M, Toda M, Ota $H$ (2007) A new species of frog allied to Fejervarya limnocharis from the southern Ryukyus, Japan (Amphibia: Ranidae). Curr Herpetol 26: 65-79

Okada N, Shedlock MA, Nikaido M (2003) Retroposon mapping in molecular systematics. Method Mol Biol 260: 189-226

Posada D, Crandall KA (1998) MODEL TEST: testing the model of DNA substitution. Bioinformatics 14: 817-818

Schleich HH, Kästle W (2002) Amphibians and Reptiles of Nepal. ARG Ganther Verlag KG, Ruggell

Shimodaira H, Hasegawa M (1999) Multiple comparison of log-likelihoods with applications to phylogenetic inference. Mol Biol Evol 16: 1114-1116

Stuart BL, Chuaynkern Y, Chan-ard T, Inger RF (2006) Three new species of frogs and a new tadpole from eastern Thailand. Fieldiana Zool NS 1543: 1-19

Sumida M, Ogata M, Kaneda H, Yonekawa H (1998) Evolutionary relationships among Japanese pond frogs infered from mitochondrial DNA sequences of cytochrome $b$ and 12S ribosomal RNA genes. Genes Genet Syst 73: 121-133

Sumida M, Kondo Y, Kanamori Y, Nishioka M (2002) Inter- and intraspecific evolutionary relationships of the rice frog Rana limnocharis and the allied species $R$. cancrivora inferred from crossing experiments and mitochondrial DNA sequences of the $12 S$ and 16S rRNA genes. Mol Phylogenet Evol 25: 293-305

Sumida $M$, Kotaki $M$, Islam MM, Djong $T H$, Igawa $T$, Kondo $Y$, Matsui M, De Silva A, Khonsue W, Nishioka M (2007) Evolutionary relationships and reproductive isolating mechanisms in the rice frog (Fejervarya limnocharis) species complex from Sri Lanka, Thailand, Taiwan and Japan, inferred from mtDNA gene sequences, allozymes, and crossing experiments. Zool Sci 24: $547-562$

Swofford DL (2002) PAUP: Phylogenetic Analysis Using Parsimony (and Other Methods), Beta Version 4.0b10. Sinauer, Sunderland, MA

Thompson JD, Higgins DG, Gilbson TJ (1994) CLUSTAL W: improving the sensitivity of progressive multiple sequence alignment through sequence weighting, position-specific gap penalties and weight matrix choice. Nucleic Acids Res 22: 4673-4680

Toda M, Nishida M, Matsui M, Ota H (1998) Genetic divergence among Southeast and East Asian population of Rana limnocharis (Amphibia:Anura), with species reference to sympatric cryptic species in Java. Zool Sci 14: 607-613

Veith M, Kosuch J, Ohler A, Dubois A (2001) Systematics of Fejervarya limnocharis (Gravenhorst, 1829) (Amphibia, Anura, Ranidae) and related species. 2. Morphological and molecular variation in frogs from the Greater Sunda Islands (Sumatra, Java, Borneo) with the definition of two species. Alytes 19: 5-28

Vences M, Thomas M, Meijden AVD, Chiari Y, Vieites DR (2005a) Comparative performance of the 16S rRNA gene in DNA barcoding of amphibians. Front Zool 2: 5

Vences M, Thomas M, Bonett RM, Vieites DR (2005b) Deciphering amphibian diversity through DNA barcoding: chances and challenges. Phil Trans R Soc B 360: 1859-1868

Vieites DR, Wollenberg KC, Andreone F, Glaw F, Vences M (2009) Vast underestimation of Madagascar's biodiversity evidenced by an integrative amphibian inventory. Proc Natl Acad Sci USA 106: 8267-8272

(Received July 7, 2009 / Accepted December 11, 2009) 